\title{
Cruzando fronteiras: a promoção de direitos com refugiados nas práticas de ensino de línguas
}

\author{
Bruno Deusdaráa* \\ Poliana Coeli Costa Arantes ${ }^{b}$ \\ Décio Rocha
}

* O autor agradece à Faperj pela concessão de bolsa do Programa Jovem Cientista do Nosso Estado (Processo no 21.4710. Edital 06/2015).

\section{Resumo}

A partir de uma experiência concreta de acolhimento a refugiados, discutimos sentidos e modalidades de política linguística subjacentes a essa prática. Partimos da noção de prática discursiva (MAINGUENEAU, 1997, 2005), por permitir refletir acerca da produção simultânea entre linguagem e mundo. $\mathrm{Na}$ sequência, relacionamos essa experiência com os desafios propostos para o campo da Linguística Aplicada. Como análise, apresentamos um perfil dos encontros de supervisão do trabalho de acolhimento, cuja experiência nos conduz a uma reflexão que ultrapassa os limites do ensino e do linguístico.

Palavras-chave: Refugiado. Ensino de Línguas. Discurso. Dispositivo. Política.

aProfessor de Linguística da Universidade do Estado do Rio de Janeiro. E-mail: brunodeusdara@gmail.com bProfessora de Língua e Literatura Alemã da Universidade do Estado do Rio de Janeiro. E-mail: polianaarantes@yahoo.com.br

cProfessor de Linguística e Análise do Discurso da Universidade do Estado do Rio de Janeiro. E-mail: rochadm@uol.com.br 


\section{Considerações iniciais}

A metáfora do território sugerida no título deste texto nos parece entrada produtiva para dar consistência ao duplo movimento que desejamos realizar: de um lado, o relato do deslocamento de nossa atuação profissional no campo da formação de professores em direção à emergência de uma nova e desafiadora intervenção nas práticas de acolhimento a refugiados, e, de outro, a experiência de ultrapassagem de fronteiras disciplinares em busca de ferramentas conceituais potentes na afirmação da coprodução da linguagem e do mundo, multiplicando os sentidos de política.

Desse modo, cruzar fronteiras remete à necessidade de sustentar o caráter singular conferido à emergência do refugiado como participante de nossas práticas, quando somos convocados a atuar no campo do ensino de línguas. Recusamos, assim, a lógica das repetições e das estabilizações endurecidas subjacentes à pretensão de se considerar o refugiado como um tipo específico de "estrangeiro" a quem se ofereceriam métodos já disponíveis e as mesmas práticas usuais em relação a quem chega ao Brasil voluntariamente - lógica que, a nosso ver, corresponde ao exercício do poder do ressentimento, com o projeto de captura do inesperado pelo já sabido.

Um primeiro movimento que julgamos necessário é afirmar que "a condição de refugiado não remete apenas ao outro que se deseja incluir. A inclusão do refugiado remete a uma rede de assistência social não plenamente assegurada a todos" (ARANTES; DEUSDARÁ; BRENNER, 2016). Para que as práticas de acolhimento não se submetam à lógica da repetição cristalizada, pareceu-nos necessário afirmar o cruzamento de outra fronteira: aquela que circunscreve o estudo da produção linguageira ao linguista e o da produção social, ao sociólogo. Em outras palavras, o tema das fronteiras é aqui abordado como experiência de dupla desmontagem: da figura excessivamente genérica do estrangeiro, em favor das multiplicidades que permitem a emergência da singularidade dos refugiados; da figura fortemente cristalizada do especialista, em busca da ação em grupos multidisciplinares, acolhendo as implicações ético-políticas desse tipo de trabalho.

Para percorrer esse processo de desmontagens, optamos por expor um percurso que se inicia pela breve apresentação 
da perspectiva teórica na qual apostamos, centrando-nos na noção de prática discursiva (MAINGUENEAU, 1997). O privilégio conferido à referida noção se deve à abertura que se afirma da coexistência entre o linguístico e o social, uma dinâmica de produção simultânea das práticas de linguagem e dos mundos possíveis. Para a desejável explicitação da reflexão a respeito do social, recuperamos elementos que nos parecem imprescindíveis, oriundos da psicologia social, com especial ênfase para a construção da noção de dispositivo. Na sequência, problematizamos o conceito atual que delimita as práticas de linguística aplicada e sua necessidade de expansão e, finalmente, discutimos uma prática de elaboração de política linguística situada para além do ensino e do linguístico stricto sensu.

\section{Apresentando o problema}

Considerando o crescimento em escala exponencial dos fluxos migratórios de refugiados como uma das marcas deste século, objetivamos refletir, neste texto, sobre linhas de ação possíveis na condução de práticas de promoção de direitos sociais com essa população, em especial pela aquisição de uma língua estrangeira.

Dados fornecidos pelo Alto Comissariado das Nações Unidas para os Refugiados (ACNUR/ONU), em 2015, indicam que 65 milhões de pessoas encontram-se em situação de refúgio. No Brasil, registra-se um crescimento de $127 \%$ da demanda, considerando o período entre 2010 e 2015. No mesmo período, os pedidos passaram de 966 , em 2010, para 28.670, em 2015 , totalizando assim $2.868 \%$ de crescimento, segundo dados fornecidos pela Polícia Federal.

Os dados são, sem dúvida, alarmantes e apresentam uma entrada de ação importante e urgente: ações que se elaboram e se realizam a partir da caracterização do perfil populacional. No Brasil, encontram-se pessoas oriundas de 79 nacionalidades distintas, sendo grupos mais numerosos, entre os solicitantes de refúgio, os haitianos, os senegaleses, os sírios, os bengaleses e os nigerianos. Já entre os refugiados, os grupos mais numerosos são os sírios, os angolanos, os colombianos, os congoleses e os libaneses. Ainda observando questões relativas a ações de ordem populacional, consideramos relevante destacar que, segundo dados fornecidos pelos arquivos da 
Cáritas-RJ ${ }^{1}$, a população de refugiados, em 2015, no Brasil, contava com $2 / 3$ de homens e $1 / 3$ de mulheres. Ainda no levantamento realizado pela entidade, contabilizou-se, no primeiro trimestre de 2016, um quadro distinto: no Rio de Janeiro, o número de mulheres já é bem próximo ao de homens, evidenciando uma gradativa alteração do perfil populacional e, por consequência, a necessidade de ações de acolhimento mais efetivamente direcionadas para as mulheres. Como se pode observar, o recurso aos dados populacionais é capaz de inspirar lutas importantes para a realização de políticas públicas, de ordem governamental, que nos implicam a todos, como cidadãos.

Essa ordem de ações se fundamenta em segmentaridades binárias, para remeter aos termos de Deleuze e Guattari (2004). Segundo os autores, somos todos segmentarizados binariamente (classe social, gênero, geração), circularmente ("eu", bairro, cidade), linearmente (família, escola, exército, profissão). A existência social, no entanto, não se restringe a esses blocos de segmentaridades, pois, em cada circunstância, os corpos expressam modos singulares de habitar, de se relacionar, de sentir. Entendemos ser importante essa distinção, por viabilizar investimentos diversos nas linhas de ação com refugiados. Nesse sentido, os dados oferecem informações da ordem da representação, ao passo que "as crenças e os desejos são fluxos marcados de quanta, que se criam, se esgotam ou se modificam, e que se somam, se subtraem ou se combinam" (DELEUZE; GUATTARI, 2004, p. 99).

Os dados sobre refúgio, supracitados, obtiveram grande repercussão na mídia empresarial brasileira, que os qualificou como maior fluxo de deslocamento de pessoas desde a Segunda

${ }^{1}$ A Cáritas Brasileira compõe, com outras 163 organizações membros, a Rede Cáritas Internacional. No Brasil, a entidade é um organismo da Confederação de Bispos do Brasil (CNBB), da Igreja Católica, e possui convênios com o Alto Comissariado das Nações Unidas para os Refugiados (ACNUR/ ONU) ecomo Ministério da Justiça, através do Comitê Nacional para Refugiados (CONARE). Guerra. Nesse cenário, eis um problema concreto que diz respeito ao ensino/aprendizagem da língua de acolhimento a refugiados, que se diferencia de uma abordagem direcionada à figura genérica dos estrangeiros:

O ensino de uma língua de acolhimento a jovens e adultos refugiados ou solicitantes de refúgio apresenta especificidades que não são as mesmas do ensino de língua estrangeira, seja por considerar de maneira excessivamente genérica essa condição de 'estrangeiro', seja por perceber um apagamento dessa inscrição multifacetada do refugiado no país de acolhida, atravessada por tensões de diferentes ordens (ARANTES; DEUSDARÁ; BRENNER, 2016). 
Para compor o presente texto, investimos no diálogo com materiais e experiências oriundos de campos disciplinares e espaços institucionais diversos, tais como o ensino/ aprendizagem de línguas em contexto de acolhimento a refugiados, a análise do discurso, a psicologia social, a linguística aplicada e o campo de orientações e elaborações de políticas linguísticas. Como professores de línguas em cursos de Licenciatura em Letras, o convite para atuar na supervisão de elaboração de materiais didáticos para o ensino de língua portuguesa a refugiados, pela Cáritas-RJ, nos lança em um campo de atuação cujas implicações ético-políticas nos entrelaçam com o modo como as angústias, os anseios, os desejos e impasses ganham corpo cotidianamente no contexto do acolhimento.

\section{Compartilhando ferramentas conceituais: prática discursiva e dispositivo}

Definindo a prática discursiva como noção integradora utilizada para "designar esta reversibilidade essencial entre as duas faces, social e textual, do discurso" (MAINGUENEAU, 1997, p. 56), o autor apresenta um posicionamento claramente contrário a uma pretensa aposta na exterioridade dos grupos frente aos discursos. Na sequência, o autor enfatiza tratar de "grupos que existem unicamente por e na enunciação, na gestão destes textos, e não aos grupos que encontrariam sua razão de ser em outro lugar" (MAINGUENEAU, 1997, p. 56). Desse ponto de vista, cabe registrar que o movimento de D. Maingueneau (1997), na elaboração inicial do conceito, restringe-se a apontar a insuficiência da noção de comunidade discursiva, como contraface da formação discursiva.

Ao delimitar sua hipótese de existência de uma semântica global (aposta na concorrência de diferentes planos - intertextualidade, dêixis, estatuto dos enunciadores, entre outros - na produção de sentido), Maingueneau (2005) avança mais explicitamente na discussão a respeito da contraface institucional dos discursos. A contribuição fundamental desse modo de conceber a prática discursiva reside em rejeitar a anterioridade do social frente ao linguístico: "não há, antes, uma instituição, depois uma massa documental, enunciadores, ritos genéticos, uma enunciação, uma difusão e, enfim, um 
consumo" (MAINGUENEAU, 2005, p. 142). Ao contrário, as diversas instâncias de elaboração, difusão e consumo da enunciação e a instituição são apreendidas a partir de uma mesma rede de regularidades semanticamente definidas.

Tal modo de conceber o vínculo entre o linguístico e o social possui implicações diversas para o analista. Destacaremos aqui duas delas: a primeira se refere à crítica ao primado da representação, e a segunda remete à necessidade de qualificar conceitualmente a produção social que se pressupõe.

É recorrente assumir o poder de representação da linguagem como sua propriedade fundamental. Sem deixar de considerar essa dimensão, gostaríamos apenas de destacar uma espécie de duplo apagamento que se institui: de um lado, "um esquecimento de que os contornos assumidos por aquilo que se 'transmite' nos textos não passa de estabilizações sempre provisórias"; de outro, "um esquecimento de que a própria situação de interação verbal investe na produção do ato que a institui e se legitima no curso mesmo de sua enunciação" (DEUSDARÁ; ROCHA, 2016, p. 332).

O mundo já não coincidiria exatamente com a representação desse mundo por intermédio da linguagem, uma vez que, ao fazer referência a esse mundo, a linguagem congela o tempo, altera distâncias, oferecendo-nos um retrato - sempre parcial - de um dado momento, o retrato de uma realidade passada e/ou de uma nova paisagem que não coincide com as coordenadas geográficas de tudo o que pode ser verificado no 'mundo ao vivo (ROCHA, 2014, p. 624).

Quanto à definição de social, consideramos como produtiva a noção de dispositivo - noção que, em diversas circunstâncias, é tratada de modo bastante heterogêneo. Para uma delimitação do problema que a noção de dispositivo evoca, recorremos à proposta foucaultiana:

(...) um conjunto decididamente heterogêneo que engloba discursos, instituições, organizações arquitetônicas, decisões regulamentares, leis, medidas administrativas, enunciados científicos, proposições filosóficas, morais, filantrópicas. Em suma, o dito e o não dito são elementos do dispositivo. O dispositivo é a rede que se pode estabelecer entre estes elementos (FOUCAULT, 2009, p. 244).

Para o autor, esses elementos heterogêneos possuem um funcionamento bastante diverso, seus efeitos (positivos ou 
negativos) estabelecem relações de ressonância ou contradição com a rede de elementos circunscrita por um dispositivo. Considerar que o dispositivo possui uma função estratégica dominante, uma estratégia sem estrategista, significa conceber seu funcionamento na constituição de malhas de poder em interação, rejeitando noções de poder como propriedade de um grupo sobre outro, ou originário do aparelho estatal. A noção de dispositivo possui, assim, o mérito de integrar as ações linguísticas e não linguísticas aos espaços institucionais, desnaturalizando a função que eles exercem sobre essas ações. Como veremos mais adiante, essa noção será importante para pensar os encontros de supervisão das práticas de acolhimento a refugiados, conferindo a elementos como frequência, modos de intervenção, propostas de atuação, entre outros aspectos, linhas que concorrem para a produção social dos grupos.

\section{Sobre Linguística Aplicada e a necessidade de expansão do conceito}

Quando nos referimos ao ensino de línguas atualmente, a menção à disciplina de Linguística Aplicada se faz, geralmente, presente. No entanto, o emprego dessa nomenclatura nos leva a pensar e a problematizar um campo de muitas tensões, sobretudo aquele que instaura um embate entre aplicabilidade e autonomicidade.

A partir da Segunda Grande Guerra e também mais tarde, em meados dos anos 80, destaca-se um momento importante de teorização que muito contribuiu para a disciplinarização do campo do ensino/aprendizagem de línguas (GALISSON, 1994 apud ROCHA, 2016), que tem caracterizado a aplicação de saberes produzidos por uma outra ciência (vertente que se denominou aplicacionista). Por outro lado, observa-se também uma tendência a atividades de teorização própria da área, que se configuraria em uma tendência autonomista.

A tendência aplicacionista, voltada para uma teorização externa, isto é, para a construção do campo do ensino/ aprendizagem de línguas por intermédio de saberes produzidos por ciências como a linguística ou a psicologia, é uma herança da linguística aplicada ao ensino de línguas iniciada nos Estados Unidos nos anos 1940. A seu turno, a tendência autonomista, dita independentista, defende um princípio de teorização interna. A passagem 
${ }^{2}$ Texto original: „In den letzten Jahrzehnten wird vor allem in Politik, Wirtschaft und in den Medien ein utilitaristisches Bild von Wissenschaft propagiert, das Ergebnisse von $\mathrm{W}$ is sen sch a f te n primär nach ihrer A n we nd barkeit, vor allem: nach ihrer ökonomischen Verwertbarkeit bewertet. Dies bedeutet ohne Zweifel eine Unterstutzung der Angewandten $W$ is senschaften, setzt sie aber einer potentiellen politischen und wirtschaftlichen Instrumentalisierung aus. Eine solche Instrumentalisierung $\mathrm{schränkt}$ jedoch die Autonomie der Wissenschaft ein und beeinträchtigt i n s b e s o n d e r e die zweckfreie Grundlagenforschung." de uma linguística aplicada a uma didática das línguasculturas ilustra bastante bem este movimento que vai do aplicacionismo ao independentismo (ROCHA, 2014, p. 113).

Assim, observam-se dois movimentos de elaboração de pesquisas nessa área: um que pretende "aplicar" teorias advindas de outras áreas; e outro que empreende esforços para a autonomização da área, incentivando as pesquisas internas e não externas à área.

Outra dicotomia também pode ser recuperada no âmbito dos estudos em linguística aplicada (angewandte Linguistik) na Alemanha, porém, lançando a questão para a possível diferença que se instauraria entre prática e teoria, ou seja, o que seria uma linguística "não aplicada"? Knapp (2011) levanta esse questionamento quando procura problematizar a dicotomia instaurada pela nomenclatura "aplicada", pois, se há uma linguística aplicada, haveria uma linguística não aplicada. Além disso, Knapp (2011) problematiza o risco que esse modo de conceber a "aplicação" apresenta às ciências aplicadas: a instrumentalização dessas ciências vem transformando-as em produtos da política e da economia. O risco é ceder às limitações impostas pelo mercado e pela política, que acabam por restringir a autonomia das investigações científicas, qualificadas de acordo com sua utilidade/funcionalidade para a sociedade.

Nas últimas décadas, está sendo propagada uma imagem utilitária da ciência, sobretudo na política, no mercado e nas mídias, apresentando-se o resultado da ciência primeiramente por meio de sua possibilidade de aplicação, avaliada principalmente de acordo com seu valor econômico. Isso significa, sem dúvida, um incentivo às ciências aplicadas, que dá margem a uma potencial instrumentalização política e mercadológica dessas ciências. Tal instrumentalização limita, contudo, a autonomia da ciência e, particularmente, as pesquisas livres de quaisquer interesses econômicos (KNAPP, 2011, p. 119 [tradução nossa]). ${ }^{2}$

Sendo assim, encontramos, no mínimo, três grandes problematizações em torno do que se configura, atualmente, como uma área de estudos que se responsabilizaria pelas pesquisas sobre ensino/aprendizagem de línguas estrangeiras. É claro que nos deparamos com uma insuficiência da nomenclatura, sobretudo se consideramos a autonomia da área frente às ciências que estariam "embasando" sua aplicação. 
Adicionalmente, estaríamos ignorando o fato de que outras linhas "teóricas" seriam "não aplicáveis", se concordássemos com a nomenclatura ora utilizada. Finalmente, como a área é necessariamente interdisciplinar e produzida por sujeitos, consideramos de suma importância retomarmos os questionamentos feitos por Rocha (2016), que problematizam a invisibilidade desses sujeitos nos manuais, nos documentos oficiais, nas universidades, nas escolas e nos cursos livres:

Quem não vê o ensino de língua estrangeira como elemento importante na formação do aluno, como um direito que lhe deve ser assegurado? Quem responde pelo fato de a língua estrangeira não ter um lugar privilegiado no currículo e por ser muitas vezes oferecida apenas em uma ou duas séries do ensino fundamental? Que instância é responsável por colocar a língua estrangeira fora da grade curricular, em Centros de Línguas, fora do horário regular e fora da escola - ou seja, fora do contexto da educação global do aluno? Lugares sintáticos vazios, não preenchidos, dão a impressão de um fato natural que acontece - a "má sorte" das línguas estrangeiras no país (ROCHA, 2016, p. 120).

Quando o ensino de línguas se dirige a refugiados, as urgências ganham visibilidade, acionando um território de ação ainda em constituição. Desse modo, a análise dos investimentos micropolíticos em sua constituição compõe um espaço importante de ação e reflexão. Vejamos a seguir de que maneira essa experiência vem se constituindo e que questões ela reenvia para o campo do ensino de línguas e da promoção de direitos linguísticos.

\section{Análise dos encontros de supervisão como dispositivo de formação}

Nesse sentido, buscamos levantar modos de produzir sentidos e, concomitantemente, políticas em torno da organização de práticas construídas para a elaboração de materiais didáticos para o curso de extensão de português para refugiados que coordenamos, realizado em parceria com a Cáritas-RJ, na Universidade do Estado do Rio de Janeiro (UERJ).

Editada a Lei 9.474/97 no Brasil, ficou definido o mecanismo para a implementação do Estatuto dos Refugiados no país. Redigida com auxílio do ACNUR e da sociedade civil, a Lei é considerada pela ONU uma das mais modernas, mais 
abrangentes e mais generosas legislações para refugiados do mundo (BARRETO, 2010, p. 19). No entanto, apesar de contemplar todos os dispositivos de proteção internacional de refugiados e criar um órgão nacional - o Comitê Nacional para os Refugiados (Conare) - para ditar a política pública do refúgio e decidir quanto às solicitações de refúgio, o Brasil não oferece qualquer programa de política nacional voltado à assistência de moradia, nem de acolhimento e de prestação de serviços emergenciais a essa população. Com a existência dessa lacuna na rede de políticas públicas, algumas organizações não governamentais, como é o caso da Cáritas Arquidiocesana, assumem a tarefa de promover ações de acolhimento aos refugiados, dentre as quais encontra-se o oferecimento do curso de português.

O curso de português para refugiados funciona sob organização e orientação da Cáritas-RJ e recebe o apoio pedagógico e a elaboração dos materiais de ensino de língua de nossa equipe do projeto de extensão "Português para Refugiados no Brasil", cadastrado no DEPEXT/SR3/UERJ e em funcionamento desde 2014. Sendo assim, todos os professores que atuam no curso são voluntários. Aqui destacamos uma primeira problematização: a formação em licenciatura não é pré-requisito para a seleção do voluntário. São pessoas, em sua maioria, que se sensibilizam com a causa dos refugiados, geralmente por intermédio da mídia, e dispõem de tempo para atuar, voluntariamente, no curso, pelo menos uma vez na semana.

A seleção dos voluntários fica a cargo da Cáritas, que realiza entrevista sobre a disponibilidade dos candidatos e seleciona, por conhecimentos declarados de língua estrangeira (inglês, francês, espanhol, árabe), os voluntários para atuação nas turmas. Como os voluntários muitas vezes trazem concepções de ensino/aprendizagem bastante próximas das experiências que tiveram como alunos, é oferecido, a cada início de semestre, pela equipe da UERJ, um curso de aperfeiçoamento e atualização aos professores voluntários, para apresentação da concepção de língua que orientou a produção do material elaborado especialmente para o curso, apresentação dos materiais e desconstruções de estereótipos a respeito do que se "deve" ou "não se deve" abordar no ensino/ aprendizagem de línguas. 
Além disso, em um dado momento, a equipe sentiu a necessidade de se reunir quinzenalmente para avaliar o processo do curso, expor dúvidas e questionamentos, intercambiar impressões, materiais e compartilhar experiências. Essas reuniões foram denominadas "supervisões" e, a partir delas, observamos modos distintos de atuação no coletivo: seja pela frequência mais ou menos recorrente dos voluntários, seja pela motivação que os conduz aos encontros, relatos das aulas, solicitação de materiais, avaliação do uso dos materiais elaborados, apresentação de dificuldades diversas do cotidiano, proposta de eventos. As motivações podem ser, portanto, acolhidas como analisadores ${ }^{3}$ das linhas de composição do grupo em supervisão.

Dessa forma, as reuniões de supervisão são muito importantes para a elaboração e reformulação dos materiais didáticos, por meio das demandas percebidas e experimentadas pelos professores voluntários em sala de aula. Nessas reuniões, o grupo pensa e elabora políticas de ensino orientadas exclusivamente à população de refugiados, situando a aprendizagem de línguas em contextos do cotidiano dos refugiados na cidade.

Para promover a análise de alguns elementos disparadores de reflexões e ações nos encontros de supervisão, desejamos ressaltar duas premissas que mantêm forte relação com o quadro teórico delineado anteriormente: i) esses encontros se realizam sempre com maior ou menor grau de integração com a rede de assistência; ii) os enunciados proferidos pelos participantes são atos de intervenção no coletivo e concorrem para a produção do próprio coletivo.

Com isso, entendemos que a produção de um grupo de atuação coletiva demanda mais do que boa vontade para a ação. É preciso não negligenciar riscos possíveis de captura da atividade de supervisão: um enquadre autoritário, no qual a superioridade do supervisor e a infantilização e incompetência

${ }^{3} \mathrm{O}$ conceito de analisador foi forjado por Félix Guattari para designar aquele ou aquilo que provoca análise, quebra, separação, explicitação dos elementos de dada realidade institucional. A esse respeito, ver Rossi e Passos (2014, p. 174). do estagiário são explicitadas, e um enquadre liberal, no qual o supervisor escamoteia as relações de poder existentes, e afirma ser um igual a seus estagiários (COIMBRA, 1989, p. 27).

Considerando o referencial adotado para dar corpo aos encontros de supervisão, explicitamos a seguir as etapas de sua realização. Cabe destacar que as etapas estão apresentadas sequencialmente apenas para fins de elaboração deste texto, 
visto que, no cotidiano das atividades, elas podem ser refeitas, conduzidas de outro modo. Afinal, "a escuta é dar lugar para o mundo do outro. E o mundo do outro nos lança no risco de desalojar o nosso próprio mundo" (DUARTE, 2015, p. 138).

a) Registro da encomenda: esse processo preliminar é feito por meio do registro de informações relevantes sobre as demandas trazidas aos encontros de supervisão pelos refugiados por meio dos professores voluntários que atuam no curso. Há uma solicitação, desde os primeiros encontros, de não organizar o material por sequência de tópicos gramaticais, mas privilegiar as situações cotidianas e delas extrair questões a serem sistematizadas;

b) análise preliminar: a equipe analisa as demandas e compila materiais (audiovisuais, imagéticos, artísticos, instrucionais, informativos, etc.) que apresentem relação com as demandas trazidas;

c) definição de eixos temáticos: os eixos temáticos são definidos a partir dos materiais coletados; a seleção dos materiais e sua organização em unidades didáticas são feitas de modo autônomo, ou seja, para cada aula um material é preparado independentemente de uma progressão; uma unidade não é pré-requisito para a outra, elas se interconectam apenas pelo tema definido;

d) elaboração e análise coletiva dos materiais: a elaboração dos materiais se realiza a partir de um esboço trazido para o grupo, que sofre muitas intervenções em reunião. Os exercícios são pensados de modo que se possam mesclar as abordagens estruturalistas, construtivistas e comunicativas de ensino, pois o objetivo principal dos exercícios não é apresentar um modelo a ser repetido, mas levar os alunos a levantarem hipóteses sobre as funções de determinadas estruturas utilizadas em um contexto específico, aproveitando ao máximo os conhecimentos de mundo que os alunos trazem de suas experiências com a própria língua materna, com outra língua estrangeira ou com a linguagem em geral. 
e) devolutiva: as unidades didáticas, depois de construídas também em sala de aula com os alunos, retornam para os encontros de supervisão para o confronto com os pressupostos que tínhamos estabelecido, a fim de se verificar se corresponderam ou não à dinâmica em sala de aula.

A partir da exposição da metodologia acima, assumimos que os materiais não podem ser produzidos de modo unidirecional e não estão finalizados antes de irem à sala de aula. A dinâmica de sala de aula faz parte, igualmente, de uma construção tanto quanto as reuniões de supervisão. A elaboração de políticas é, portanto, uma engrenagem que gera um processo cíclico, sobretudo porque se assume que a supervisão é um dispositivo e que os alunos são sujeitos que têm direitos, sobretudo o direito de participar da construção dos materiais que serão utilizados em sala de aula. Com efeito, os alunos também participam da engrenagem, não compõem apenas um campo de "aplicação", pretensamente exterior à elaboração.

Colocar em prática um modo de conceber a política linguística orientada às perspectivas de ações singulares dos alunos é possível desde estes que sejam vistos como sujeitos de direitos.

Pensar em uma educação para a singularidade (isto é, uma educação voltada a..., orientada pela singularidade) não significa, pois, opor à massificação da escola moderna uma espécie de individualização, que estaria tão ao gosto burguês. Pensar uma educação orientada pela singularidade significaria subverter o próprio conceito moderno de educação (GALLO, 2007, p. 296).

As devolutivas se estabelecem como campo, inclusive, de exercício de direito dos professores de participarem do processo de elaboração das políticas linguísticas que direcionam as práticas em sala de aula. Esse modo de conceber a construção coletiva, militante e científica das políticas linguísticas nos parece importante de ser incentivado, sobretudo em meio a um mercado editorial que disputa financiamentos para a produção massificada de conteúdos, articulado a um modo de produção que desautoriza os professores a criar seus materiais 
em consonância com as práticas e os contextos singulares que vivenciam.

Estar atento aos impasses e hesitações nesse processo nos autoriza a participar do processo de ensino/aprendizagem de modo horizontal, pois a discussão em grupo nos ajuda a todos a construir possibilidades e direcionamentos distintos, uma vez que, a partir do olhar do outro, somos convocados a nos colocar em outro território, que nos incentiva a ultrapassar as fronteiras de nosso próprio modo de agir diante de uma dificuldade. Em outras palavras, "apreender os sentidos e significados do trabalho e sua (con)formação histórica, material e imaterial, mais que prestar serviços, é produzir a si mesmo" (DUARTE, 2015, p. 136).

\section{Uma prática situada para além do ensino e do linguístico stricto sensu}

Falamos até o momento de um trabalho realizado em sala de aula, cujo objetivo é ensinar a língua portuguesa a refugiados de diferentes origens. Na verdade, se recorremos a termos como "sala de aula", "professor" e "aluno" para descrever a atividade em questão, trata-se de um raciocínio que tomamos de empréstimo ao domínio do ensino de línguas na escola, recurso que nos garante algum conforto - e familiaridade - na narração de uma experiência que ainda nos é, em larga medida, desconhecida. Adiantaremos aqui nossa posição a respeito, deixando os argumentos que lhe dão sustentação para os próximos parágrafos: a experiência desenvolvida junto a refugiados não pode ser tratada como uma atividade de ensino de línguas segundo se pratica regularmente nas escolas e nos cursos de línguas; tal experiência implica a comunhão do linguista e do analista do discurso, recolocando em questão o encontro da ciência com a política.

Iniciemos nossa argumentação por esse último tópico: o encontro da ciência com a política. Um encontro no mínimo problemático, tendo em vista os debates que vêm sendo travados, a exemplo da distância que Calvet (2010) busca construir entre "política linguística" e "politologia linguística". As polêmicas se multiplicam em um território pródigo em nomenclaturas. Com efeito, desde que, em 1959, 
${ }^{4}$ Les définitions du syntagme politique linguistique sont nombreuses, mais eles font toujours référence à des pratiques et à des actants, pratiques qui concernente l'intervention sur la forme des langues, sur les rapports entre les langues, leur place dans la société, etc., et actants qui relèvent d'instances étatiques ou militantes. o norueguês Einar Haugen propôs, com base em Weinreich (1954), o conceito de language planning para se referir à "elaboração de uma ortografia normativa, de uma gramática e de um dicionário para guiar o uso escrito e oral em uma comunidade linguística não homogênea" (LAROUSSI, 2010, p. 183), muito se tem falado a respeito: "planejamento linguístico", expressão correspondente ao termo empregado por Haugen que, ao final dos anos 1960, foi estendida a qualquer tipo de intervenção para regulamentar problemas sociolinguísticos; "ordenamento/manejo linguístico", tradução do francês aménagement linguistique, termo preconizado por Corbeil e em voga no Québec para se referir, segundo Loubier (2008, p. 10), tanto aos processos de regulação sociolinguística oficial (políticas, leis, decretos, etc.), quanto aos processos de autorregulação sociolinguística promovidos por práticas sociais indiretas (familiares, educativas, econômicas, religiosas, etc.); "normalização linguística", termo utilizado na literatura catalã para designar situações em que uma língua dominada entra em um processo de reapropriação de funções sociais que passaram a ser exercidas em uma língua dominante; glotopolítica, expressão cunhada por sociolinguistas franceses (Marcellesi, Guespin) para se referirem a toda e qualquer forma de ação de gestão da interação linguageira por parte da sociedade (compreendendo-se tanto as ações governamentais quanto as de iniciativa de qualquer cidadão).

Em meio a tal diversidade terminológica, queremos aqui centrar a atenção na já mencionada diferença estabelecida por Calvet (2010) entre o conceito de "políticas linguísticas" e o de "politologia linguística". Diz o autor:

As definições do sintagma política linguística são numerosas, mas elas sempre fazem referência a práticas e a actantes, práticas que concernem à intervenção sobre a forma das línguas, sobre as relações entre as línguas, seu lugar na sociedade, etc., e actantes que participam de instâncias estatais ou militantes (CALVET, 2010, p.45) ${ }^{4}$.

Convencido de que o cientista não é o ator de políticas linguísticas, mas sim aquele que tem autoridade para falar das políticas linguísticas implementadas por autoridades estatais, Calvet localiza no conceito de politologia linguística a possível margem de ação do pesquisador: 
Nossa abordagem [a abordagem dos cientistas] inscreve-se no que proponho chamar de politologia linguística, isto é, a vontade de análise científica dos textos legislativos, das ações, da promoção ou da defesa das línguas; resumidamente, o discurso científico que assumiria o conjunto das políticas linguísticas e de suas traduções práticas (CALVET, 2010, p. 45)5.

O projeto que anima a reflexão de Calvet não é tão simples quanto poderia parecer à primeira vista, pelo fato de nele haver uma certa ambiguidade: por um lado, o autor vê o científico e o político como práticas de naturezas diversas, e sustentar ambas as práticas conduziria o sujeito a ocupar uma posição ambígua, razão pela qual o autor preconiza o engajamento politológico para se alcançar sucesso no plano da política linguística (CALVET, 2010, p. 53-54); por outro lado, o encontro do científico e da militância parece ser inevitável, o que vem configurar uma posição que nos interessa particularmente defender. Diz o autor: "cientistas e militantes, estamos incessantemente encurralados, divididos entre duas posturas" (CALVET, 2010, p. 54 [tradução nossa]) ${ }^{6}$.

Para a finalidade do presente artigo, o que aqui nos interessa é justamente essa superposição de lugares que julgamos inevitável - e mesmo desejável. O fato de a tradição acadêmica haver reservado o termo "política linguística" para fazer referência a ações executadas pelo Estado não impede, por óbvio, que identifiquemos a dimensão política do trabalho realizado em ambos os casos, seja lá qual for o termo escolhido para a ele nos referirmos. Assim, rejeitando toda forma de divórcio entre agentes estatais que decidem e

5 Notre approche releve donc de ce que je propose d'appeller la politologie linguistique, c'est-à-dire la volonté d'analyse scientifique des textes législatifs, des actions, de la promotion ou de la défense des langues, en bref le discours scientifique qui prendrait en charge l'ensemble des politiques linguistiques et de leur traductions pratiques.

${ }^{6}$ Scientifiques et militants, nous sommes sans cesse coincés, tiraillés entre deux postures. executam uma ação incisiva de políticas estatais e cientistas que não fariam senão falar a respeito, o que não ratificamos, na realidade, é o lugar de saber-poder que se pretende conferir à ciência, o qual, sustentado pela lógica dos especialismos, funciona muito convenientemente como álibi para o seu descomprometimento frente às escolhas éticas que implicarão a construção de uma dada qualidade de social. A divisão entre aqueles que sabem e os que não sabem é um dos pilares do capitalismo para a produção de subjetividades controladoras e subjetividades tuteladas.

Se anunciamos no título deste subitem a opção por uma prática situada para além do ensino e do linguístico, é porque não se trata meramente de passar conhecimentos 
de língua portuguesa a um certo público. Trata-se, antes, de propiciar encontros que provoquem uma interlocução em língua portuguesa, na certeza de que os textos produzidos e os laços que então se criam são promotores de uma certa qualidade de sociabilidade que trará ao refugiado aquilo que lhe falta: a garantia de estar construindo um aqui e um agora estreitamente implicados com a produção de sua subjetividade.

Essa é uma das razões pelas quais não se pode compreender a experiência de trabalho junto ao sujeito refugiado como mera atividade de ensino de língua a um estrangeiro. $\mathrm{O}$ refugiado não pode ser entendido como um estrangeiro numa terra que ele, de alguma forma, escolheu para ser a sua (nova) terra. Por isso também não se exige uma licenciatura em língua portuguesa àqueles que desejam participar da experiência de "sala de aula", uma vez que, detentores de um saber epilinguístico enquanto falantes (CULIOLI, 1981), poderão ainda dispor de outros dispositivos que assegurarão um trabalho produtivo, como as sessões de supervisão e a exposição coletiva dos materiais produzidos pelos voluntários para as "aulas". Com efeito, compartilhando tais espaços com uma equipe de linguistas que, além de uma perspectiva discursiva no tratamento da língua, também são professores de português, logra-se um alto grau de implicação com o trabalho realizado. Uma qualidade que, certamente, nada tem de exclusivo de tal modalidade de atuação no campo do "ensino" de línguas, mas que em geral encontra-se ausente do espaço das licenciaturas, se considerarmos as graves limitações que ainda hoje pesam sobre a formação de professores.

\section{Considerações finais}

Com o presente texto, pretendemos diversificar os sentidos e as modalidades de política subjacentes às práticas de acolhimento a refugiados, sobretudo em um momento que ainda nos convoca a problematizar a ausência dessa matéria nos cursos de formação de professores em geral, como se a prática política pudesse ser desmembrada das ações didáticopedagógicas realizadas por esses sujeitos.

Se partimos do pressuposto de que toda ação no mundo constitui-se como um ato político, pois determina escolhas 
motivadas em detrimento de outras, não podemos negar a tentativa falida de construção de uma "realidade" que se diz "neutra". Para embasar nossos pressupostos, a disciplina de políticas linguísticas tem contribuído muito, sobretudo para nos fazermos atentos às escolhas que estamos determinando enquanto sujeitos nos cenários de ensino/aprendizagem de línguas, pois parece haver ainda dificuldades em determinadas áreas em reconhecer o caráter político de suas pesquisas e intervenções no mundo, como se algumas disciplinas fossem mais ou menos aderentes à lógica política e, portanto, completamente incompatíveis com essas noções intrínsecas aos atos de produção de textos (RAJAGOPALAN, 2004).

Afirmar a singularidade das práticas de acolhimento a refugiados frente a uma genérica figura do "estrangeiro" também constituiu objetivo central de nosso texto, sobretudo porque o trabalho com uma comunidade como essa não pode estar em consonância com as atividades exercidas com grupos de estrangeiros que estão no país por motivações bastante distintas daquelas dos refugiados e que, por esse motivo, requerem abordagens da língua que os qualifiquem para intervenções cotidianas de acesso às políticas de saúde, de educação e de direitos, em geral, por meio do uso da língua nessas situações para a garantia de exercício de direitos civis.

Fornecer, para o campo da Linguística Aplicada, uma definição de social em que se investe na noção de "dispositivo" também se articulou a esse modo de caracterizar a abordagem de ensino/aprendizagem de língua portuguesa para refugiados, principalmente, porque "o campo de estágio não foi uma superfície sobre a qual aplicaríamos técnicas ou operaríamos conceitos, pois o entendíamos a partir de um fazer capaz de disparar mudanças em longo prazo" (DUARTE, 2015, p. 141).

Nesse sentido, buscamos qualificar a atuação em grupo não como a ação de um coletivo que antecederia as decisões, os impasses vividos em conjunto: "os grupos sujeitos assumem seus próprios desejos e instituem novas relações sociais, tornando-se capazes de romper com os processos identificatórios com outras instituições que criam o não saber sobre si mesmas e sobre seus próprios funcionamentos" (COIMBRA, 1989, p. 28). Finalmente, procuramos apresentar nossa experiência de definição coletiva de parâmetros de 
políticas linguísticas em um processo horizontal que contou com a participação de todos os envolvidos nas atividades de ensino/aprendizagem de português para refugiados.

\section{REFERÊNCIAS}

ARANTES, P. C. C.; DEUSDARÁ, B.; BRENNER, A. K. Língua e alteridade na acolhida a refugiados: por uma micropolítica da linguagem. Fórum Linguístico, Florianópolis, v. 13, n. 2, p. 1196-1207, jul. 2016.

BARRETO, L. P. T. F. A Lei Brasileira de Refúgio: sua história. In: BARRETO, L. P. T. F. (org). Refúgio no Brasil: a proteção brasileira aos refugiados e seu impacto nas Américas. Brasília: ACNUR, Ministério da Justiça, 2010.

CALVET, L-J. Parler des langues, parler les langues une approche politologique. Iles d Imesli, Tizi Ouzou, Argélia, n.2, p. 45-55, 2010. Disponível em: < http://revue.ummto.dz/index. php/idi/article/view/215 >. Acesso em: 05 jan. 2017.

COIMBRA, C. M. B. A supervisão institucional como intervenção sócio-analítica. Psicologia Ciência e Profissão, Brasília, v. 9, n. 1, p. 26-28, 1989. Disponível em: < http://scielo.br/pdf/pcp/v9n1/08. pdf $>$. Acesso em: 04 jan. 2017.

CULIOLI, A. Systèmes de représentations linguistiques et métalinguistiques. (mimeo). 1981. Disponível em: < http:// unesdoc.unesco.org/images/0004/000465/046590FB.pdf $>$. Acesso em: 06 jan. 2017.

DELEUZE, G.; GUATTARI, F. Mil Platôs: capitalismo e esquizofrenia. vol. 3. Rio de Janeiro: Ed. 34, 2004.

DEUSDARÁ, B.; ROCHA, D. Corpos em encontro e efeitos incorporais: articulação linguagem/extralinguístico. Psicologia \& Sociedade, v. 28, p. 331-340, 2016.

DUARTE, D. A. A supervisão enquanto dispositivo: narrativa docente do estágio profissional em psicologia do trabalho. Interface: comunicação, saúde, educação. Botucatu, v. 52, n. 19, p.133-44, 2015.

GALLO, S. Em torno de uma educação voltada à singularidade: entre Nietzsche e Deleuze. In: LINS, D, (org). Nietzsche/ Deleuze: imagem, literatura e educação. Rio de Janeiro: Forense Universitária, 2007, p. 288-302. 
KNAPP, K. Angewandte Linguistik in Deutschland - eine Disziplin? In: Histoire Épistémologie Langage: Linguistique appliquée et disciplinarisation. v. 33, n. 1, p. 117-128, 2011. Disponível em: < http://www.persee.fr/doc/hel_07508069_2011_num_33_1_3210 >. Acesso em: 04 jan. 2017.

FOUCAULT, M. Microfísica do poder. Rio de Janeiro: Graal, 2009.

LAROUSSI, F. Les politiques linguistiques des pays maghrébins. Un essai d'évaluation. Iles d Imesli, TiziOuzou, Argélia, n. 2, p. 183-196, 2010. Disponível em: < http://revue.ummto.dz/index. php/idi/article/view/224/150 >. Acesso em: 28/12/2016.

LOUBIER, C. Langues au pouvoir - politique et symbolique. Paris: L'Harmattan, 2008.

MAINGUENEAU, D. Gênese dos discursos. Curitiba: Criar, 2005. Novas Tendências em Análise do Discurso. Campinas: Ed. da Unicamp; Pontes, 1997.

ROCHA, D. Representar e intervir: linguagem, prática discursiva e performatividade. Linguagem em (Dis)curso, Tubarão, SC, v. 14, n. 3, p. 619-632, set./dez. 2014. Disponível em: < http://www.scielo.br/pdf/ld/v14n3/1518-7632ld-14-03-00619.pdf >. Acesso em: 04 jan. 2017.

Da Linguística Aplicada à Didática das línguas: pela diversidade de pesquisas favoráveis ao trabalho com língua estrangeira. Linguagem \& Ensino. Pelotas, v.19, n.1, p. 99-123, jan./jun. 2016. Disponível em: < http://www.rle.ucpel.tche.br/ index.php/rle/article/view/1414/922 >. Acesso em 04 jan. 2017. ROSSI, A.; PASSOS, E. Análise institucional: revisão conceitual e nuances da pesquisa-intervenção no Brasil. Epos. v.5, n.1, Rio de Janeiro, 2014. Disponível em: < http://pepsic.bvsalud.org/ scielo.php?script=sci_arttext\&pid=S2178-700X2014000100009 >. Acesso em: 04 jan. 2017. 


\section{Abstract \\ Crossing boundaries: the promotion of refugee's rights through language teaching practices}

From a concrete experience of receiving refugees, we discuss the meanings and modalities of language policy presents in this practice. We start from the notion of discursive practice (MAINGUENEAU, 1997, 2005), to reflect on the simultaneous production between language and social world. In the sequence, we relate this experience to the challenges proposed for the field of Applied Linguistics. As analysis, we discuss the supervision meetings, whose experience leads us to a reflection that goes beyond the limits of teaching and linguistics.

Keywords: Refugee. Language Teaching. Discourse. Device. Policy. 